\title{
O lugar do pensamento no ensino da Filosofia
}

Paulo Henrique Fernandes Silveira ${ }^{8}$

\section{Resumo}

É possível ensinar Filosofia? É possível ensinar a pensar? Para filosofar é preciso conhecer a história da Filosofia? Quais as condições para o exercício do pensamento num curso de Filosofia? Para Immanuel Kant, não basta conhecer os pensamentos dos grandes filósofos para aprender a filosofar. A Filosofia exige a ousadia e a maturidade intelectual de quem reconhece a necessidade de pensar por conta própria. Para Martin Heidegger, vivemos uma época na qual as pessoas se dedicam a muitas atividades, mas pensam pouco. Mesmo nas universidades e nas escolas, os estudantes não parecem dispostos a enfrentar experiências e acontecimentos que inspirem novos pensamentos. O propósito deste artigo é investigar, a partir das reflexões de Kant e de Heidegger, bem como das análises de outros filósofos e pedagogos que tratam do tema, o lugar do pensamento no ensino da filosofia.

Palavras-chave: pensamento; história da filosofia; ensino; autodidatismo; experiência.

\section{The place of thinking in the teaching of Philosophy}

\begin{abstract}
Would it be possible to teach Philosophy? Would it be possible to teach how to think? In order to philosophize, does one have to know about the history of Philosophy? Which are the proper conditions to the exercise of thought in a Philosophy courses? As Immanuel Kant states, knowing the greatest philosophers' ideas does not suffice for one to learn how to philosophize. Philosophy demands audacity as well as intellectual maturity from those who acknowledge the necessity of thinking on their own. For Martin Heidegger, these are times in which people dedicate themselves to a great deal of activities, being the process of thinking scarce. Even in university and school contexts, learners don't seem to be willing to face experiences and events which would inspire new thinking. This paper aims at investigating the place of thinking in the teaching of Philosophy. Such investigation will be based on Kant's and Heidegger's reflections as well as contributions from other scholars in the field of Philosophy and Pedagogy.
\end{abstract}

Key words: thinking; history of philosophy; teaching; autodidacticism; experience.

8Doutor em Filosofia (USP). Professor da Faculdade de Educação da Universidade de São Paulo. E-mail:
paulohenrique.silveira@bol.com.br 
Uma palavra, uma melodia, uma história, uma linha, chaves no vento para que minha mente fuja.

Versos de Bob Dylan

Pelas mais diversas e díspares razões, uma tese apresentada nas últimas páginas da Crítica da razão pura, o mais célebre livro de Immanuel Kant, influencia a didática de inúmeros filósofos e pedagogos: não se pode aprender filosofia, "apenas se pode, no máximo, aprender a filosofar" (Kant, 2001, p. 660). Ao contrário de certas ciências que podem ser aprendidas e ensinadas, não há um saber filosófico aceito por todos. Talvez, indaga Kant, nunca encontremos respostas necessárias e universais para as questões fundamentais da filosofia, mais especificamente: "O que posso saber?; O que devo fazer?; O que me é lícito esperar?; O que é o homem?” (2003, p. 42).

De qualquer modo, argumenta Kant, nada nos impede de formular novas respostas que se somem ou se sobreponham às que foram levantadas pelos outros autores: "Todo pensador filosófico constrói, por assim dizer, sua própria obra sobre os destroços de uma obra alheia; mas jamais se erigiu uma que tenha sido estável em todas suas partes" (Ibidem, p. 42). Um professor que queira ensinar seu aluno a filosofar "não deve ensinar pensamentos, mas a pensar; não deve carregá-lo, mas guiá-lo, se quer que ele seja apto no futuro a caminhar por si próprio" (Kant, 2003, p. 174). Para filosofar, é preciso inventar; quem se finca nos pensamentos dos outros, na melhor das hipóteses, sabe imitar (Kant, 2001, p. 660). Num certo sentido, mesmo conhecendo de cor e salteado as teses e os conceitos dos filósofos, muitos eruditos não sabem pensar.

Os homens que não fazem uso do seu entendimento sem a direção de um tutor são culpados por sua minoridade. Segundo Kant, a preguiça e a covardia são responsáveis pela falta de autonomia: "Se tenho um livro que faz as vezes de meu entendimento, um diretor espiritual que por mim tem consciência, um médico que por mim decide a respeito de minha dieta, etc., então não preciso me esforçar" (Kant, 1985, p. 100). Como crianças que não foram encorajadas a andar sozinhas, tais pessoas não ousam pensar por conta própria (Ibidem, p. 102).

Sendo uma área do conhecimento cuja investigação parece ser interminável, a filosofia autoriza e exige a criação de novos conceitos; porém, Kant aconselha a leitura atenta dos textos clássicos, que mais não seja, para que o aluno exercite sua argumentação: "quem quer aprender a filosofar tem o direito de considerar todos os sistemas da filosofia tãosomente como uma história do uso da razão e como objetos do exercício de seu talento filosófico" (Kant, 2003, p. 43).

\section{Pensar na história da filosofia}

Nas últimas décadas, na iminência da filosofia conquistar mais espaço no currículo das escolas brasileiras, ocorreram nas universidades inúmeros debates a respeito da 
importância e da especificidade dessa disciplina. As ideias de Kant sobre o ensino da filosofia tiveram destaque nessas discussões

À primeira vista, essas ideias apontam para uma dificuldade didática, uma vez que não cabe ao professor de filosofia ensinar pensamentos, mas ensinar a pensar. Num texto seminal dos anos cinquenta, Jean Maugüé, um dos missionários franceses que contribuíram para a estruturação do departamento de filosofia da Universidade de São Paulo, reconhece que um curso de filosofia deve ensinar os alunos a filosofar, e, justamente por essa razão, "não pode apresentar-se como um conjunto de conhecimentos objetivamente transmissível" (1954, p. 226) ${ }^{9}$. Para que isso seja possível, complementa Maugüé (Ibidem, p. 229), o professor precisa oferecer uma cultura vasta e precisa e um bom conhecimento da história da filosofia. Como destaca Paulo Arantes, a posição de Maugüé sobre o ensino envolvia um imperativo técnico: não se aprende filosofia sem conhecer bem os clássicos, e dans le texte (1994, p. 72). Não obstante, pelos relatos de Antonio Candido, que foi aluno de Maugüé, ficamos sabendo que o seu compromisso com a leitura dos clássicos não o inibia de refletir em suas aulas sobre "as paixões, os namoros, os problemas de família, o noticiário dos jornais, os problemas sociais, a política" (citado por Arantes, 1994, p. 65). Além disso, "não é corajosamente filósofo senão aquele que cedo ou tarde expressa seu pensamento acerca das questões atuais" (Maugüé, 1954, p. 228).

Há muitas maneiras de abordar a história da filosofia. Provavelmente, não ensinaria a pensar um curso que a apresentasse como uma mera "sucessão linear de fatos e de teorias a serem memorizadas mecanicamente pelos educandos" (Silveira, 2007, p. 144). Segundo Mario Porta, essa maneira de trabalhar com a história da filosofia é irrelevante e cumpre, na melhor das hipóteses, uma função informativa (2011, p. 144). Por outro lado, um curso pode perpassar a história da filosofia com o intuito de compreender os problemas e analisar as soluções oferecidas pelos autores clássicos. Nas palavras de Franklin Leopoldo e Silva: "Em filosofia não há aquisição propriamente dita, mas apenas a familiaridade progressiva com certa ordem do pensar que é a ordem da inteligibilidade" (1993, p. 802). Investigando o repertório de questões, de argumentos e de conceitos da história da filosofia, um curso torna possível "o trânsito da pseudo-segurança da linguagem cotidiana e do pensamento de senso comum à verdadeira segurança do discurso criticamente fundamentado" (Ibidem, p. 802). É temeroso interpretar ao pé da letra o adágio "não se aprende filosofia", como nas outras disciplinas que fazem parte do currículo do ensino médio, num curso de filosofia: "há o que aprender, há o que memorizar, há técnicas a serem dominadas, há, sobretudo, uma terminologia específica a ser devidamente assimilada" (Silva, 1992, 163).

\footnotetext{
${ }^{9}$ Certamente, não aprenderá a filosofar e a pensar por conta própria o aluno que simplesmente repetir os conteúdos transmitidos pelos livros ou pelos professores. Todavia, como analisa Leandro de Lajonquière, podese compreender a transmissão, seja no ensino ou na psicanálise, não como o deslocamento de um vírus, mas como uma maneira de adquirir aquilo que nos foi doado: "Freud gostava de lembrar: 'deves adquirir aquilo que herdas'. Isto é, o não iniciado nada recebe sem se implicar” (2011, p. 861).
} 
Por mais original que possa ser um pensamento, não há como ignorar a importância da história da filosofia: "toda filosofia depende, em certo sentido, das que a precederam, uma vez que as reposições dos problemas e as transfigurações dos conceitos se fazem em relação a um determinado contexto de tradição, e nenhuma filosofia é inseparável de uma polêmica implícita que o filósofo mantém com os antecedentes, com os contemporâneos e até consigo próprio" (Silva, 1986, p. 155).

O que ocorre em muitas pesquisas filosóficas também pode pautar o ensino da filosofia nos colégios: um trabalho de reconstrução dos problemas e dos conceitos da história da filosofia. Em suas análises sobre o tema, Porta distingue a reconstrução racional da histórica. A primeira visa destacar os aspectos lógicos de um argumento, de uma tese ou de um sistema filosófico. A segunda procura restituir o contexto de debate e de investigação no qual um pensamento foi elaborado. Esse trabalho de reconstrução nos permite perceber com clareza os antigos problemas e nos abre a possibilidade de elaborar novos problemas (Porta, 2011, p. 146). Como defendem Sílvio Gallo e Walter Kohan, o diálogo com a história da filosofia pode se dar como: "uma forma de desvio, de pensar o novo repensando o já dado e pensado" (2001, p. 194).

Não pensam por conta própria aqueles que se prendem às ideias do passado, todavia, como bem ressalva Ronai Rocha: "aqueles que desconhecem o passado podem se ver condenados a repeti-lo" (2000, p. 164). Ao invés de negar a autonomia do pensamento, um professor que tenha a história da filosofia como referencial pode procurar "naquilo que foi pensado o que nos faz pensar" (Silva, 1993, p. 803). Sem dúvida, há muita coisa importante para se ensinar num curso de filosofia: problemas, teses, conceitos que podem ajudar o aluno a escapar da imediaticidade da opinião e fazer com que ele identifique "como sendo seu este outro que é a cultura" (Horn, 2009, p. 75).

\section{Pensar sobre o pensamento}

Por melhores que sejam as diretrizes de um curso de filosofia, vivemos num momento propício para o pensamento? É isso o que os alunos procuram nas escolas? Numa série de textos dos anos cinquenta, Martin Heidegger analisa essas questões e afirma em tom de lamento: "há vários séculos o homem vem agindo demais e pensando de menos" (2004, p. 4). Mesmo entre aqueles que se interessam pela filosofia, na maior parte dos casos, há uma disposição para estudar os pressupostos dos grandes pensadores ${ }^{10}$, mas não para aprender a pensar. A preocupação constante dessas pessoas com a filosofia cria-lhes, tão somente, a ilusão de que estão sempre pensando (Ibidem, p. 5).

Ao analisar duas célebres frases sobre a origem e o significado da filosofia, a saber, a

\footnotetext{
${ }^{10}$ Para Rodrigo Gelamo, o ensino da filosofia precisa realizar um trabalho de problematização e de resistência aos pressupostos da própria filosofia (2008, p.172). Questionando esses pressupostos, talvez encontremos outros caminhos para o pensamento.
} 
de Platão: "é verdadeiramente de um filósofo esta paixão - o espanto; pois não há outra origem imperante da filosofia que este", do Teeteto, 155d, e a de Aristóteles: "pelo espanto os homens chegam agora e chegaram antigamente à origem imperante do filosofar", da Metafísica, 982b, Heidegger percebe no espanto (thaumázein) uma paixão (páthos) que propicia a reflexão filosófica $\left(2006\right.$, p. 30) ${ }^{11}$. Na essência do pensamento filosófico há uma experiência passional na qual o indivíduo é convocado a reagir à realidade que o cerca. Para vivermos essa experiência, precisamos aprender a esperar sem criar esperanças ou expectativas, "pois o estar em expectativa já se prende a uma representação e ao seu objeto representado" (Heidegger, 2001, p. 43).

Um aprendiz de carpinteiro aprende a fazer armários, camas e coisas semelhantes, a lidar com vários instrumentos e com as mais diversas madeiras, mas também aprende a se familiarizar com pessoas desconhecidas que um dia utilizarão suas obras. Por analogia, recomenda Heidegger, um professor de filosofia precisa ensinar seu aluno a aprender a pensar sobre o que ainda possa lhe ocorrer: "o mestre autêntico, de fato, não ensina outra coisa senão a aprender" (2004, p. 15).

Essas ideias de Heidegger influenciam toda uma geração de filósofos do século vinte. Pautados por suas análises sobre os significados do pensamento e da filosofia, Cornelius Castoriadis, Jacques Derrida, Jean-François Lyotard e Gilles Deleuze trazem outros elementos para interpretação do adágio de Kant. Para esses autores, a autonomia do pensamento pressupõe o autodidatismo daquele que aprendeu a pensar por conta própria. Não se trata do autodidatismo de um self-made man que não pôde frequentar uma escola, mas do autodidatismo de quem decide tornar-se mestre de si mesmo. Sendo assim, de maneira alguma um curso de filosofia pode censurar o aluno que não se satisfaz em repetir os pensamentos do seu mestre ou dos grandes autores.

A filosofia tem um compromisso, afirma Castoriadis, com a totalidade do pensável; não apenas com a totalidade do que já foi pensado, mas com a totalidade do que ainda há para pensar (1999, p. 17). O aluno que deseja pensar por conta própria precisa investigar o que permanece impensado. Segundo Derrida, "o mestre é somente um mediador que deve apagarse" (1986, p. 16). O lugar do mestre precisa permanecer vago para que o aluno ouse ocupá-lo, para que ele ouse aprender consigo mesmo, para que ele ouse tornar-se seu próprio mestre. Por outro lado, ser autodidata, explica Lyotard, não significa que não aprendemos nada dos outros, mas "que não aprendemos nada deles, se eles não nos ensinam a desaprender" (1986, p. 35). A reflexão filosófica precisa incitar "a desestabilização das evidências recebidas, inclusive e, sobretudo, as filosóficas" (Castoriadis, 1999, p. 27). Retomando a possibilidade do espanto, pontua Deleuze, repetimos indefinidamente a experiência do pensamento: "como se o pensamento só pudesse começar, e sempre recomeçar” (2006, p. 193). O ensino da

\footnotetext{
${ }^{11}$ Sobre esse tema, escreve Maria Aranha: "O ensino da Filosofia supõe um compromisso com a vida, para que se possa recuperar, em um mundo por demais pragmático, o que os gregos já chamavam de capacidade de admirar-se, ou seja, do espanto diante do óbvio, do corriqueiro, das certezas sedimentadas" (2001, p. 118).
} 
Filosofia não implica, somente, na aprendizagem de certos conteúdos, mas na transformação do homem a partir do questionamento da experiência e da elaboração de novos conceitos. Para aventurar-se no universo do que ainda há para pensar, argumenta Lílian do Valle, o aluno precisa estar disposto a criar a si mesmo "como alguém que jamais se foi e que antes nunca existiu" (2009, p. 476).

Todavia, esse autodidatismo não pode ser transmitido ou ensinado. Ainda que o mestre seja um autodidata, se ele se colocar como um exemplo a ser imitado ou se ele tentar determinar a pessoa que seu aluno deve se tornar, certamente, ele não lhe ensinará a pensar e a aprender por conta própria. Nesses termos, como defende Sigmund Freud, a educação é uma profissão impossível (1991, p. 249) ${ }^{12}$. A posição do professor, reconhece Marilena Chauí, é muito arriscada: "ele está sempre a um passo de tornar-se guru, de assenhorear-se do lugar do mestre e manter os alunos, para sempre, na condição de discípulos” (1980, p. 40). Pensando no autodidatismo do aluno, o mestre precisa fazer um "esforço cotidiano para que o seu lugar permaneça vazio" (Ibidem, p. 39). É importante, sugere Marcelo Pereira, que o mestre ative o desejo de saber do aluno mostrando-lhe o seu próprio desejo de saber (2008, p. 200).

\section{Pensar na sala de aula}

A par dessas análises e reflexões, pode-se vislumbrar uma perspectiva sobre a especificidade da filosofia no âmbito das outras disciplinas e áreas do conhecimento e propor uma postura didática frente às possibilidades do seu ensino. Como a história, a matemática e outras disciplinas, ao longo de séculos de uma intensa produção, a filosofia construiu teorias que interpretam as mais diversas facetas da experiência humana. Por certo, o aprendizado desses conteúdos é importante para a formação intelectual e cultural de qualquer aluno, seja no ensino médio ou na Universidade. Os conceitos, as estruturas lógico-argumentativas e os estilos de pensamento dos filósofos nos auxiliam na compreensão da natureza, da política e do homem e abrem uma alternativa de diálogo com as artes e as ciências. Além disso, uma leitura filosófica que desdobre os pressupostos e os subentendidos de um texto (Favaretto, 1995, p. 81), promove um exercício de pensamento e desenvolve técnicas de interpretação da linguagem.

Desde a criação da democracia na Grécia, a filosofia se apresenta, principalmente, como uma força interrogante (Silva, 1993, p. 799). Ao contrário dos filodoxos, daqueles que se iludem com as aparências e com as opiniões, os filósofos questionam quase tudo o que veem e o que escutam. Para exercer essa função, analisa Celso Favaretto, é fundamental que o professor trabalhe em sala de aula com determinados dispositivos de pensamento:

\footnotetext{
${ }^{12}$ Para Rinaldo Voltolini, a afirmação de Freud de que a educação é uma profissão impossível não aponta para um fim "inexequível", mas para um fim "inalcançável" (2011, p. 25). Pelo menos um dos fins da educação, a autonomia do pensamento, está sempre por se alcançar.
} 
"elaboração conceitual, procedimentos argumentativos e problematização" (2008, p. 12). Apresentando diferentes interpretações para os textos; interrogando os fundamentos das teses e das ideias; avaliando o alcance e a universalidade dos conceitos; e analisando a coerência e a relação entre os argumentos, um curso de filosofia instiga a elaboração de links que podem aproximar uma época de outra época, uma causa de uma manifestação, um livro de outro livro, uma situação de um sentimento, uma imagem de um pensamento, uma palavra de uma coisa, uma música de um autor, uma pessoa de outra pessoa.

Em muitos casos, as respostas dos filósofos do passado para certos problemas perderam a atualidade, mas algumas das suas questões podem ser recolocadas ao indagarmos sobre nossa realidade; por exemplo, ainda faz sentido problematizarmos, seguindo os passos de Platão, a respeito das dificuldades pelas quais os estudantes passam no processo de formação, e é pertinente interrogarmos, com Rousseau, sobre a origem da desigualdade entre os homens. Nesses tempos em que "a 'maioridade' intelectual, social e moral dos usos de nossas vidas, prometida pelo Iluminismo, cede à autonomização da economia com respeito ao controle humano" (Matos, 2000, p. 13), o estudo e o debate sobre algumas questões filosóficas podem abrir espaço nas salas de aula para o pensamento e a emancipação. Numa das mais enigmáticas ideias da filosofia, Parmênides afirma que "ser e pensar são a mesma coisa". Arrisquemos uma interpretação: assim como a filosofia, enquanto atividade que cria pensamentos, está sempre por se fazer, o homem, enquanto ser, está sempre por se refazer.

Um curso de filosofia pode promover situações que levem alunos e professores a pensar na sala de aula: construindo experiências nas quais as pessoas se vejam afetadas por aquilo que escutam, leem e discutem (Larrosa, 2006, p. 90); abrindo espaço para os mais inusitados encontros com livros, ideias, imagens, sons e pessoas (Deleuze, 1998, p. 8); e gerando acontecimentos de resistência aos clichês e ao ritmo frenético das nossas atividades diárias (Fabbrini, 2005, p. 24) ${ }^{13}$. O pensamento demanda uma disponibilidade, nos ensina Paulo Freire: "disponibilidade a tocar e a ser tocado, a perguntar e a discordar, disponibilidade à vida e a seus contratempos" (2013, p. 131). É difícil para qualquer professor de filosofia ensinar a si mesmo e a seus alunos a pensar, mas sua sala de aula pode estar disponível para essas experiências, encontros e acontecimentos.

Uma palavra, uma melodia, uma história, uma linha; talvez, atentos e apaixonados pelos detalhes da experiência e livres das amarras da opinião, professor e alunos de um curso de filosofia possam transformar a sala de aula num lugar diferente, num lugar onde se cultive o prazer de pensar.

Submetido em 22 de maio de 2013. Aprovado para publicação em 06 de agosto de 2013.

\footnotetext{
${ }^{13}$ Nessa mesma linha de interpretação, acrescenta Walter Kohan: "Suspeitamos que se o pensar é um encontro, ensinar a pensar tem a ver com propiciar esse encontro, com preparar as condições de sua irrupção" (2003, p. 234).
} 


\section{REFERÊNCIAS}

ARANHA, Maria. Filosofia no ensino médio: relato de uma experiência. In: KOHAN, W.; GALLO, S. (orgs). Filosofia no ensino médio. Petrópolis: Vozes, 2000.

ARANTES, Paulo. Um departamento francês de ultramar: estudos sobre a formação da cultura filosófica uspiana (uma experiência nos anos 60). São Paulo: Paz e Terra, 1994.

CASTORIADIS, Cornelius. Feito e a ser feito: as encruzilhas do labirinto V. Tradução de Lílian do Valle. Santa Teresa: DP\&A, 1999.

CHAUI, Marilena. Educação e ideologia. In: Educação \& Sociedade, Campinas, 2 (5), p. 24-40, 1980.

DELEUZE, Gilles. Diferença e repetição. Tradução de Luiz Orlandi e Roberto Machado. Rio de Janeiro: Graal, 2006.

; PARNET, Claire. Diálogos. Tradução de Eloisa Araújo Ribeiro. São Paulo: Escuta, 1998.

DERRIDA, Jacques. Les antinomies de la discipline philosophique: lettre préface. In: et al. La grève des philosophes: école et philosophie. Paris: Osiris, 1986.

FABBRINI, Ricardo. O ensino de filosofia: a leitura e o acontecimento. In: Trans/Form/Ação, Marília, 28 (1), p. 7-28, 2005.

FAVARETTO, Celso. Notas sobre o ensino de filosofia. In. MUCHAIL, S. (org). Filosofia e seu ensino. São Paulo: EDUC, 1995.

Prefácio (Ensino de filosofia e currículo). In. ROCHA, R. Ensino de filosofia e currículo. Petrópolis: Vozes, 2008.

FREUD, Sigmund. Análisis terminable e interminable. In: Obras completas, vol. 23. Buenos Aires: Amorrortu, 1991.

FREIRE, Paulo. Pedagogia da autonomia. São Paulo: Paz e Terra, 2013.

GELAMO, Rodrigo. Pensar sem pressupostos: condição para problematizar o ensino da 
filosofia. In: Pro-posições, 19, 3 (57), Campinas, p. 161-174, 2008.

HEIDEGGER, Martin. Que é isto - filosofia? Identidade e diferença. Tradução de Ernildo Stein. Petrópolis: Vozes; São Paulo: Duas Cidades, 2006.

Serenidade. Tradução de Maria Madalena Andrade e Olga Santos. Lisboa: Instituto Piaget, 2001.

What is called thinking? Tradução de J. Glenn Gray. Nova Iorque: Perennial Library, 2004.

HORN, Geraldo. Ensinar filosofia: pressupostos teóricos e metodológicos. Ijuí: Unijuí, 2009.

KANT, Immanuel. Crítica da razão pura. Tradução de Manuela Pinto dos Santos e Alexandre Fradique Morujão. Lisboa: Fundação Calouste Gulbenkian, 2001.

Lógica. Tradução de Guido Antônio de Almeida. Rio de Janeiro: Tempo Brasileiro, 2003.

Textos seletos. Tradução de Raimundo Vier e Floriano de Souza Fernandes. Petrópolis: Vozes, 1985.

KOHAN, Walter. Infância. Entre educação e filosofia. Belo Horizonte: Autêntica, 2005.

; GALLO, Sílvio. Crítica de alguns lugares-comuns ao se pensar a filosofia no Ensino Médio. In: KOHAN, W.; GALLO, S. (orgs). Filosofia no ensino médio. Petrópolis: Vozes, 2001.

LAJONQUIÈRE, Leandro de. A mestria da palavra e a formação de professores. In: Educação \& Realidade, Porto Alegre, 36 (3), p. 849-865, set/dez, 2011.

LARROSA, Jorge. Sobre la experiencia. In. Aloma: revista de psicologia, ciències de l'educació i de l'esport, Barcelona, 19, p. 87-112, 2006.

LYOTARD, Jean-François. Le cours philosophique. In: et al. La grève des philosophes: école et philosophie. Paris: Osiris, 1986.

MATOS, Olgária. A arte do bem-viver: cidadania, amizade. In: KOHAN, W.; LEAL, 
B.;

RIBEIRO, Á. (orgs). Filosofia na escola pública. Petrópolis: Vozes, 2000.

MAUGÜÉ, Jean. O ensino de filosofia: suas diretrizes. In: Kriterion, Belo Horizonte, 29-30, p. 224-234, 1954.

PEREIRA, Marcelo. A impostura do mestre. Belo Horizonte: Argumentum, 2008.

PORTA, Mario. Filosofia e história da filosofia: uma reflexão sobre as relações de texto e contexto. In: Cognitio-Estudos: revista eletrônica de filosofia, 8 (2), p. 141-148, 2011.

ROCHA, Ronai. Filosofia como educação de adultos. In: In: KOHAN, W.; GALLO, S (orgs). Filosofia no ensino médio. Petrópolis: Vozes, 2000.

SILVA, Franklin Leopoldo e. Currículo e formação: o ensino da filosofia. In: Síntese nova fase, Belo Horizonte, 20 (63), p. 797-806, 1993.

História da filosofia: centro ou referencial. In: NIELSEN NETO, H. (org). O ensino de filosofia no $2^{\circ}$ Grau. São Paulo: Sofia editora SEAF, 1986.

Por que a Filosofia no segundo grau. In: Revista Estudos Avançados, São Paulo, 6 (14), p. 157-166, 1992.

SILVEIRA, Renê. Teses sobre o ensino de filosofia no nível médio. In:

GOTTO, R. (orgs). Filosofia no ensino médio: temas, problemas e propostas. São Paulo: Loyola, 2007.

VALLE, Lílian do. Educação impossível. In: Educação, Santa Maria, 34 (3), p. 473 486, 2009.

VOLTOLINI, Rinaldo. Educação e psicanálise. Rio de Janeiro: Zahar, 2011. 